
www.globaljournalseries.com; Info@globaljournalseries.com

\title{
STIGMATIZATION \\ AS \\ CORRELATE \\ OF DISPOSITION TO UTILIZATION OF HIV/AIDS SERVICES AMONG STUDENTS IN TERTIARY INSTITUTION IN CALABAR METROPOLIS
}

\author{
L. U. AKAH; V. C. EMERIBE AND E. AHUEANSEBHOR
}

(Received 8, August 2012; Revision Accepted 16, January 2013)

\begin{abstract}
This study investigated stigmatization as correlate to utilization of HIV/AIDS services among students in tertiary institutions in Calabar metropolis. Three hypotheses were postulated to guide the study. Literature related to the variables was reviewed accordingly. Survey research design was adopted for the study. Sample of two hundred (200) students were utilized for the study using stratified random and convenience sampling techniques. Structured questionnaire designed by the researchers was the main instrument used for data collection. The instrument was subjected to validation by experts in relevant fields. The reliability estimate of the instrument was established through the test re-test reliability method. To test the hypotheses, Pearson Product Moment Correlation Analysis was adopted. The hypotheses were tested at .05 level of significance. The result of the analysis revealed that stigmatization significantly relate with disposition to utilization of HIV counseling services, HIV test/screening services and adherence to HIV treatment among tertiary institution students in Calabar Metropolis. Based on the findings of the study, it was recommended that government and nongovernmental agencies should embark on public enlightenment campaign to educate the public on the need for VCT utilization.
\end{abstract}

KEY WORDS: Stigmatization, Correlate, Disposition, Utilization HIV/AIDS

\section{BACKGROUND OF THE STUDY}

HIV/AIDS related stigma and discrimination exist in the world over. Calabar being a fast growing tourist attraction not only locally, but internationally is faced with the possibility of increased HIV infections, especially during their annual Christmas carnival celebrations. The celebrations which last for a full month attract tourists from different parts of the world. The after effect of this and other related tourist activities as often lamented by health care givers are increase in unwanted pregnancies; increased incidence of STDs, resulting from the wanton display of sexual promiscuity. This no doubt raises concern among health workers and concerned individuals and NGOs. After such tourism activities, the metropolis and its environs live with the aftermaths of increase in cases of abortions, child abandonment after delivery, increase in STDs, etc. The challenge now becomes how to manage the cases of infections and to curb its spread. Cases of HIV infection has been found to be on the rise in Calabar

L. U. Akah, Department of Human kinetics \& Health Education University of Calabar, Calabar, Nigeria

V. C. Emeribe, Department of Human kinetics \& Health Education University of Calabar, Calabar, Nigeria

E. Ahueansebhor, Department of Human kinetics \& Health Education University of Calabar, Calabar, Nigeria 
metropolis since the inception of Christmas carnival and other tourism related events. Even though Cross River State Government and other related agencies are doing their bid to enforce zero new infections and non stigmatization on HIV/AIDS parents, a number of factors such as tourism related programmes seem to undermine their efforts.

A preliminary survey conducted at the University of Calabar medical center that houses a Voluntary Counseling and Testing (VCT) outfit showed that counselees abscond appointments in most cases for retest HIV-confirmation test and anti Retroviral Therapy (ART) regimen after first or second visits, for confirmed cases. This can lead to worsening of health condition of victims and increase in the spread of HIV/AIDS. This may be due to fear of stigmatization. Stigmatization is manifested differently in countries, communities, religious settings, cultural groups, and among individuals (Chan, 2005). They occur alongside other forms of stigma and discrimination such as racism and homophobia, and are directed towards people living with HIVAIDs or their relatives.

Oti (2009) Shisam (2007) and Smith (2006) stated that one of the major challenges confronting the fight against the spread of HIV/AIDS-related stigma among others include prejudice, negative attitudes, abuse and maltreatment directed at people living with the virus. These manifest in various forms such as being shunned or neglected by family members, friends, peers, and the wider community; and poor and humiliating treatment in health care facilities and educational institutions. UNAIDS (2010) and Nwokoye (2006) opined that such acts of stigmatization can bring about psychological damage and can ngatively affect the disposition of victims towards testing and counseling services.

Adesola (2009) and Ihejiamaizu (2002) maintained that stigmatization account for the rapid spread of HIV/AIDS in developing countries. Ihejiamaizu (2002) observed that in central Africa, AIDs victims and their families are banned from getting water at public sources and even attending church services. Chan (2005) observed that the discrimination and stigmatization against people living with HIV/AIDS (PLWA) has greatly affected the level at which people avail themselves the opportunity for voluntary counselling and testing. The United Nation Secretary General Ban Kimoon, according to Chan (2005) stated that stigmatization remains the single and most important barrier to public action against HIV/AIDS. It is the main reason many people are afraid to see a doctor to determine whether they have the disease or to seek available care where necessary.

Stigmatization helps make HIV/AIDS the silent killer, because people fear the degradation associated with it.

Adeji (2008) underscored the fact of HIV/AIDs in sub-Saharan Africa. He observed that annual HIV/AIDs positive births in Nigeria stood at an estimate of 73,550 for 2005; 74, 500 for 2006; and was expected to reach 75, 780 for 2010 because stigmatization has directly worked against the prevention and control of this disease that has ravaged the world. The scholar stressed that stigmatization against people living with HIV/AIDS has not affected only the victims but other members of the society who have deliberately refused to subscribe to available counsellinig testing and treatment services.

Katawa and Ecik (2011) observed that stigmatization has undermined the ability of individuals, families and societies to protect themselves and provide support and reassurance to those affected. This hinders the efforts targeted at stemming the epidemic. In the same vein, Oti (2009) opined that fear of stigmatization and discrimination is the main reasons why people are reluctant to be counseled, tested, or to take antiretroviral drugs. This has greatly affected the fight against the scourge of the disease significantly in sub-Saharan Africa. This study is thus, another effort to examine how stigmatization relates with the utilization of HIV/AIDs services among students in tertiary Institutions in Calabar metropolis of Cross River State, Nigeria. Even though the state Government is campaigning for zero new infections and against stigmatization, the researcher sought to establish how stigmatization whether perceived or real, affects the disposition of students in tertiary institutions towards the utilization of HIV/AIDS related services.

\section{Methodology}

The researchers adopted the survey research design, for this study. This design was deemed appropriate since the study aimed at describing and interpreting existing conditions of how stigmatization correlate with the utilization of HIV/AIDs services among students in tertiary institutions. 
The population of the study consisted of students of tertiary institutions located in Calabar metropolis. These youths form the main age group on display during the Calabar Christmas carnival and other related tourism events and appear to be the age category with rising cases of HIV infections. Calabar metropolis is made up of two local government areas: Calabar south Local Government Area and Calabar municipality. The three main tertiary institutions located in the metropolis are University of Calabar with a population of 10,152 ; Cross River University of Technology with a population of 2,220; and College of Health Technology with a population of 1,103; which includes both male and female students. These male and female populations of 13,475 comprised the population of the study.

A total number of two hundred (200) students utilized for the study were drawn from three tertiary institutions in Calabar metropolis. 100 students were drawn from University of Calabar, while 50 students were drawn from Cross River University of Technology and College of Health Technology respectively. One hundred subjects were delibrately drawn from the University of Calabar due to its significantly high population compared with the other two institutions.

The main instrument used for data collection was a structured questionnaire designed by the researchers. The questionnaire was divided into two sections. Section A was designed to collect the respondent $\hat{\mathbf{S}}$ personal data such as sex, age, etc. Section B contained sixteen (16) items on a four point Likert-type scale designed to probe the dependent and independent variables under investigation. The items enquired into stigmatization and the respondent $\hat{\Phi}$ disposition to utilization of the various HIV/AIDS related care services. Four items were designed for each of the variables that were investigated.

The questionnaire was designed by the researchers with the assistance of two experts from the Department of Human Kinetics \& Health
Education \& Educational Statistics/measurement and Evaluation respectively. The recommendations of these experts were taken into consideration in the production of the final draft utilized for the generation of data.

To determine the reliability of the instrument (questionnaire), a trial test was done using twenty 20 students drawn from the Nursing School of the University of Calabar Teaching Hospital. Test retest method of reliability estimate was utilized for the pilot study. Here the researcher gave the same group of respondents the questionnaire to complete twice, with an interval of two weeks. The scores for the two sets of data were correlated. The reliability co-efficient ranged from 0.79-0.83.

Three hypotheses designed to guide the study for which data were generated are postulated below.

(i) Stigmatization does not significantly affect tertiary institutions studentsô disposition towards utilization of HIV counseling service in Calabar metropolis.

(ii) Stigmatization does not significantly relate with counselees disposition towards the utilization of HIV test/screening services among tertiary institution students in Calabar metropolis.

(iii) There is no significant relationship between stigmatization and the disposition of tertiary institution students towards adherence to HIV treatment in Calabar metropolis.

\section{RESULTS}

\section{Hypothesis One}

Stigmatization does not significantly relate with tertiary institution students disposition towards utilization of HIV counseling service in Calabar metropolis. Pearson Product Moment Correlation Analysis was considered the most appropriate statistical technique employed to test the hypothesis. The result of the analysis is presented in Table 1. 
Pearson Product Moment Correlation Analysis of the Relationship between Stigmatization and Utilization of HIV Counseling Services $(\mathrm{N}=\mathbf{2 0 0})$

\begin{tabular}{|c|c|c|c|c|}
\hline Variables & $\sum_{\sum \mathbf{x}} \mathbf{x}$ & $\begin{array}{l}\sum x^{2} \\
\sum y^{2}\end{array}$ & $\sum x y$ & r-value \\
\hline \multirow[t]{2}{*}{ Stigmatization } & 3463 & 6153 & & \\
\hline & & & 89844 & $0.61^{*}$ \\
\hline HIV Counseling services & 3692 & 6429 & & \\
\hline
\end{tabular}

*Significant at 0.5 , critical $r=195, \mathrm{df}=198$

The result of the statistical analysis as presented in Table 1 revealed that the calculated $r$-value of 0.61 is greater than the critical r-value of .195 at 0.05 level of significance with 198 degrees of freedom. Thus, the null hypothesis was rejected. This therefore showed that there is a significant positive relationship between stigmatization and students disposition towards utilization of counseling services among tertiary institution students in Calabar metropolis.

\section{Hypothesis Two}

Stigmatization does not significantly relate with counselees disposition towards the utilization of HIV test/screening services among tertiary institution students in Calabar metropolis. Pearson Product Moment correlation analysis was considered the most appropriate statistical technique employed to test the hypothesis. The result of the analysis is presented in Table2.

Table 2

Pearson Product Moment Correlation Analysis of the Relationship between Stigmatization and Utilization of HIV test/screening Services $(N=200)$

\begin{tabular}{lllll}
\hline Variable & $\sum \mathbf{x}$ & $\sum \mathbf{x}^{2}$ & $\sum x y$ & r-value \\
\hline $\begin{array}{l}\text { Stigmatization } \\
\begin{array}{l}\text { HIV test/Screening } \\
\text { Services }\end{array}\end{array}$ & 3912 & 6907 & & \\
\hline
\end{tabular}

*Significant at .05 , critical $r=.195, \mathrm{df}=198$

The result of the statistical analysis as presented in Table 2 showed that the calculated r-value of 0.67 is greater than the critical r-value of .195 at 0.05 level of significance with 198 degrees of freedom. With this result, the null hypothesis was rejected. This implies that there is a significant positive relationship between stigmatization and the disposition of students towards utilization of HIV test/screening services among tertiary institution students.

\section{Hypothesis three}

There is no significant relationship between stigmatization and the disposition of tertiary institution students towards adherence to HIV treatment in Calabar metropolis. Pearson Product Moment Correlation analysis was considered the most appropriate statistical technique employed to test this hypothesis. The result of the analysis is presented in Table 3 . 
Table 3

Pearson Product Moment Correlation Analysis of Relationship between Stigmatization and Students disposition to adherence to HIV treatment

$(\mathrm{N}=\mathbf{2 0 0})$

\begin{tabular}{|c|c|c|c|c|}
\hline Variables & $\begin{array}{l}\sum x \\
\sum y\end{array}$ & $\begin{array}{l}\sum x^{2} \\
\sum y^{2}\end{array}$ & $\sum x$ & r-value \\
\hline \multirow[t]{2}{*}{ Stigmatization } & 3463 & 6153 & & \\
\hline & & & 98433 & 0.75 \\
\hline \multicolumn{4}{|c|}{ Students' adherence } & \\
\hline
\end{tabular}

The result of the statistical analysis as presented in Table 3, revealed that the calculated r-value of 0.75 is greater than the critical r-value of .195 at 0.05 level of significance with 198 degrees of freedom. With this result the null hypothesis was rejected. This showed that there is a significant relationship between stigmatization and students disposition to adherence HIV treatment, in tertiary institutions.

\section{DISCUSSION}

The result of the hypothesis one revealed that stigmatization significantly relate with tertiary institution students disposition towards utilization of HIV counseling service in Calabar metropolis. The findings is in agreement with the view of Bharat, Agglelon and Taylor (2001) who observed that there exist a current relationship between stigmatization and utilization of HIV counseling. The fear of being stigmatized if the individual $\hat{\Phi}$ test showed positive to HIV, is a major factor affecting the level of students in tertiary institution disposition to HIV counseling. Majority of the subjects $(76 \%)$ indicated indisposition even to discuss the issue with a counselor. Further probe showed that they fear being associated with anything that is HIV/AIDS related. AIDs stigma according to Smith (2006) does not only make it difficult for people to come to terms with HIV and manage their lives but discourage them from embarking on re-test counseling for HIV. WHO (2004) observed that the fear of stigmatization and discrimination is the main reason why people are reluctant to undertake counseling for HIV. Shisam (2007) in the same vein posited that AIDs related stigma is one of the most important barriers to HIV counseling. This study showed that individuals who have not been tested of HIV but are aware that the disease is associated with stigmatization and discriminations are reluctant to go for counseling. The researcher further observed that this stigmatization, whether perceived or real has the capacity to discourage the utilization of HIV/AIDS counseling services.

The second hypothesis revealed that stigmatization significantly affected counselees disposition to utilization of HIV test/screening services among tertiary institution students in Calabar metropolis. The finding is in line with the view of Shisam (2007). He observed that stigmatization against people living with HIV accounts for the unwillingness of many Kenyans who have not known their HIV status to undertake HIV testing. Nwokoye (2006) in the same vein noted that stigma remains the most important barrier to public action on HIV/AIDs. It is the main reason why too many people are afraid to see a doctor or a laboratory scientist to determine whether they have the disease or to seek treatment. The implication of the finding of this study is that stigma helps make HIV/AIDS the silent killer because it plays down on counseleesô utilization of HIV testing/screening services. The counselee fears the social disgrace of being tested positive for HIV. The other dimension is that, carriers of the virus will continue to spread the disease to innocent members of their families or communities. The number of infections may be on the hike if the problem of stigma is not dealt with. UNAIDS (2010) also observed that stigmatization against people living with HIV/AIDS by their families is most dehumanizing to the victim. In majority of developing countries families are the primary 
care givers when somebody falls ill. There is clear evidence that families play an important role in providing support and care for people living with HIV/AIDS. However, not all family responses are supportive. HIV positive members of the family can find themselves stigmatized and discriminated against at the home. Many victims are not allowed to eat from the same plate with siblings and their loved ones. Some are not allowed to even touch their relatives.

The result of hypothesis three revealed that there is significant relationship stigmatization and the disposition towards adherence to treatment among tertiary institution students in Calabar metropolis. The findings is in line with the view of Katawa (2011) who asserted that each time they think of returning to care centers or health facilities, the negative treatment sometimes experienced from caregivers discourage them from attending their clinic days even when their drugs are finished. The study concluded that stigmatization against people living with HIV/AIDS especially by the health care giver definitely affects victims utilization and adherence to treatment. The implication is that if care givers who are trained for the purpose of providing care and relief to ailing victims of cases such as HIV/AIDS, cannot be held in trust and confidence, both victims and prospective victims may find themselves stuck with regards to health care. The society at large may thus be heading for an unprecedented number of infections and deaths resulting from HIV/AIDS. Adesola (2009) maintained that of all manner of stigma, that which comes from health care givers demoralizes the patient and affects their treatment compliance much more. Nwokoye (2006) similarly opined that at the moment orthodox treatment remains the cogent option for HIV/AIDS. Something urgently must be done to curb the stigmatization and ill treatment from care givers towards HIV/AIDS victims or health care seekers in general, since orthodox treatment remains the only proven and cogent option for HIV/AIDS patients.

\section{CONCLUSION}

Stigmatization is evil and should be discouraged by all means by stake holders. HIV/AIDs as an infection can take its toll on an individual. More need to be done to make the public understand that it can be controlled and managed effectively to allow victims to live their normal lives and achieve desired goals and aspirations.

\section{RECOMMENDATIONS}

Based on the findings of this study the following recommendations were made:

1. Public awareness campaign against stigmatization should be stepped up with practical objectives.

2. Government should put up a legislation that would protect the rights of HIV/AIDS patients against stigmatization. Punishment for professionals and individuals who engage in stigmatization should be well spelt out.

3. Government and non-governmental agencies should organize seminars for health workers, to educate them on how to treat and handle HIV/AIDS patients. Showing them tender care and respect that would reinforce the confidence of HIV/AIDS victims on health care givers should be the objective of such seminars.

4. Health workers should educate and encourage people living with HIV/AIDS on the importance of adhering to the treatment regimen.

5. Demystifying of HIV/AIDS may be helpful in curbing the effect of stigmatization on victims. HIV/AIDS should be portrayed to public as any other infectious disease that can be controlled and effectively managed.

\section{REFERENCES}

A desola F. A., 2009. HIV/AIDS and migration. Lagos: Unilag Press.

Adeji, G. A., 2008. HIV/AIDS and urbanization. Population and Development Review, No. 29 p.3.

Bharat, S., Aggleton, P. and Taylor, P., 2001. India HIV and AIDs related discrimination, stigmatization and denial. UNAIDS Publication.

Chan R. S., 2005. Prenatal screening for HIV A review of the evidence of the US Preventive Service Task Force. Annals of internal medicine 143 (1) 32-36. 
Inejiamaizu, E. C., 2002. Issues in population policy and Health care administration. Owerri: African Scholars Publishing Company.

Katawa, D. L. and Ecik, C., 2011. The youths perspective on HIV/AIDS counseling and testing (HCT) in Gulu, Northern Uganda. A cross-sectional study design. Journal of Medicine Services, 2 (4) 812-820

Nwokoye, C. A., 2006. Social-cultural aspects of HIV/AIDs infection in Nigeria. African Journl of Medicine and Medical Sciences, 3(4) 15-30.

Oti, E. O., 2009. Fertility behaviour among people living with HIV/AIDS (PLWHA) in selected States of south eastern nigeria. Seminer Paper.

Shisam, P. C., 2007. Internalized stigma, discrimination and depression among men and women living with HIV/AIDS in cape town south Africa. Journal of Social sciences, 14, 1813-1823.

Smith, P. C., 2006. HIV/AIDS and urbanization. Population and Development Review, 28, 11-15.

UNAIDS, 2010. Report on the global HIV/AIDS epidemic. Family Health International, Geneva Switzerland. Retrieved from Http//www.ncbi.nim.nih.gov/pmlacttest 1874211 (Accessed August 7, 2011). 